\title{
Relation between blood sugar level and random activity during food and water deprivation'
}

\author{
James R. Misanin, Nelson F. Smith and Byron A. Campbell \\ PRINCETON UNIVERSITY
}

\begin{abstract}
Blood sugar level and stabilimeter activity were measured in rats at several stages of food deprivation and water deprivation. Significant negative correlations between blood sugar level and activity were found in both food and water deprived Ss.
\end{abstract}

\section{Problem}

The pattern of spontaneous activity of mammals during hunger and thirst varies from species to species and is influenced by several known external determinants such as temperature, ambient sensory stimulation, and the type of measuring equipment used (Campbell, 1963). In contrast the internal determinants of activity during deprivation states are still unknown even though research on the problem was begun decades ago. One possible mechanism suggested by early investigators was that the blood sugar level may determine, at least in part, the duration and intensity of activity during food deprivation, but the data obtained at the time did not offer very strong support for this position (e.g., Shirley, 1928).

Several reasons exist for re-opening investigation of the relation between random activity and blood sugar level; the most important being that previous research was directed only at the correlation of blood sugar level and activity at low levels of food deprivation when changes in both are minimal. The present study investigated the relationship between blood sugar level and stabilimeter activity in rats at several degrees of both food and water deprivation. Water deprivation groups were included because of the frequently reported interdependence of the two states.

\section{Method}

The Ss were 55 male albino rats of the SpragueDawley CD strain between 250 and $315 \mathrm{gm}$.

The experiment was carried out in a moderately sound isolated, temperature and light controlled room that has been described elsewhere (Campbell, 1963). The temperature during the experiment was $45^{\circ} \mathrm{F}$ and the relative humidity varied between 50 and $75 \%$. A 12-hr. day-night light cycle was used. The experimental room contained $217 \times 8 \times 5$ in wire mesh stabilimeter cages in individual cubicles. When $\mathrm{S}$ moved from one side of the cage to the other a microswitch was activated which in turn operated a remote electromagnetic counter. Maintenance of the Ss was carried out daily between 10:00 and 11:00 a. m. and blood samples were taken at that time. Activity was not recorded during this period.

Each $\mathrm{S}$ was adapted to the cage for three days and then deprived of food or water according to a predetermined deprivation schedule.

The food deprived (FD) Ss were sacrificed after 1, 2 or 3 days of deprivation and water deprived (WD) Ss after 1,3 or 5 days. There were six Ss in each group reported except the two-day FD and the two-day WD groups which contained seven and five Ss respectively. In addition a control (0 deprivation) group of six Ss was run.

Animals were sacrificed by a spino-cervical separation and at least $3 \mathrm{cc}$ of blood collected in test tubes prepared with a preservative and anticoagulant. The entire process of sacrifice and blood collection required approximately $30 \mathrm{sec}$. Shortly after samples were collected, blood sugar determinations were made using the Nelson-Somigyi method. The blood sugar determinations were made by a commercial laboratory that had no knowledge of the experimental conditions imposed on the Ss.

\section{Results}

Figure 1 shows activity and blood sugar level as a function of type and duration of deprivation. The activity score is the median number of crossings for the 24-hr. period preceding sacrifice and blood sugar level in mg. per cent. The left panel of the figure shows that as food deprivation progresses blood sugar decreases and activity increases. Kruskal-Wallace analyses of variance showed both effects to be significant ( $P$ 's $<.02$ ). A rank order correlation between activity and blood sugar levels on Ss in the 0,1,2 and 3-day food deprived groups gave a correlation of $-.67(\mathrm{P}<.01)$. In contrast to the food deprived rats, the water deprived groups showed relatively little systematic change in blood

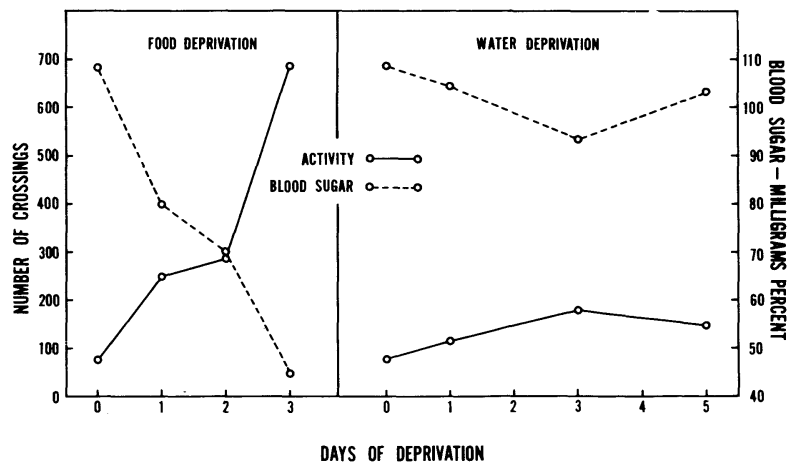

Fig. 1. Activity and blood sugar level as a function of days food deprivation (left panel) and water deprivation (right panel). 
sugar level or activity throughout the course of deprivation. Although both measures remained within the normal range, there was still a significant correlation $(\mathrm{r}=-.36, \mathrm{P}<.05)$ between blood sugar level and activity in the 0,1,3 and 5-day water deprived Ss.

\section{Diseussion}

The finding of significant correlations between blood sugar level and activity revives the possibility that there is an interdependence between the two variables. While this finding by no means indicates a causal relationship between the two variables, it seems appropriate to consider two hypothetical mechanisms that might underlie the correlation. One possibility is that low blood sugar level heightens activity either by acting as an instigating stimulus or by lowering response thresholds to activity eliciting stimuli. From this point of view activity would continue until the blood sugar level was raised through eating or until fatigue produced a temporary cessation of activity. Upon recovery from the activity-produced fatigue the animal would again become active. Another possibility is that spontaneous activity is involved in the short-term regulation of blood sugar. It is generally believed that brief, strenuous activity raises blood sugar (Christophe \& Mayer, 1958). Thus it is possible that low blood sugar serves as a stimulus for activity which would subsequently be followed by another period of hypoglycemia and, in turn, another period of heightened activity.
While both of these mechanisms are logically possible, the present data cannot be viewed as offering support for either process. Moreover, because of the divergent activity patterns evoked during conditions of deprivation it seems unlikely that any unitary mechanism could have widespread generality. None-the-less, the finding of a significant negative correlation between blood sugar level and spontaneous activity indicates that further research on the interrelationship of the two factors is called for.

\section{Referenees}

CAMPBELL, B. A. Theory and research on the effects of water deprivation on random activity of the rat. Symposium on thirst and the regulation of body water, Florida State University, May, 1963.

CHRISOPHE, J., \& MAYER, J. Effects of exercise on glucose uptake in rats and men. J. appl. Physiol., 1958, 13, 269-272.

SHIRLEY, MARY. Studies in activity III. The influence of phosphate feeding on activity; the relation of blood sugar to activity. Amer. J. Physiol. , 1928, 83, 377-383.

\section{Note}

1. Supported in part by Public Health Service Grant MH-1562, from the National Institute of Mental Health and in part by National Science Foundation Research Grant GB-235. 